\title{
Holographic Interferometry Method for Assessment of Static Load Stress Distribution in Dog Mandible
}

\author{
Tomie N. CAMPOS ${ }^{1}$ \\ Lena K. ADACHI ${ }^{1}$ \\ Jose E. CHORRES ${ }^{1}$ \\ Antonio C. CAMPOS ${ }^{2}$ \\ Mikiya MURAMATSU ${ }^{3}$ \\ Marco A. GIOSO ${ }^{4}$
}

\begin{abstract}
${ }^{1}$ Department of Dental Prosthesis, School of Dentistry; ${ }^{2}$ Department of Maxillofacial Surgery, Prosthesis and Traumatology, School of Dentistry; ${ }^{3}$ Institute of Physics; ${ }^{4}$ School of Veterinary Medicine and Animal Sciences, University of São Paulo, São Paulo, SP, Brazil
\end{abstract}

\begin{abstract}
This study compared the transmission of tensions in fresh, fixed and macerated dog mandibles in order to clarify the diversity of behavior of bone tissues under dry and moist conditions. Double-exposure holographic interferometry was applied and holograms were obtained from 12 fresh hemi-mandibles under static load (control group), which were randomly assigned to 2 groups: 6 were fixed in $10 \%$ formalin and 6 were macerated. The specimens were submitted to the same initial force and their respective holograms were obtained. Analysis of the holograms showed that the fresh specimens transmitted significantly less tension than the fixed and macerated ones $(\mathrm{p}<0.05)$, and the tension direction was different. An average two-fold tension increment was observed in the experimental conditions. The holographic interferometry method was efficient in quantifying and qualifying tension transmission. However, depending on the type of analysis, the anatomical specimens must be fresh because macerated specimens will produce different results.
\end{abstract}

Key Words: holographic interferometry method, bone tissue, mandible, stress distribution.

\section{INTRODUCTION}

Several fields of Dentistry, such as Prosthodontics, Endodontics, Orthodontics, Periodontists and other, have employed various techniques to evaluate stresses distribution, including photoelasticity, mechanical models, finite element analysis and strain gauge systems (13). All of these techniques have advantages and disadvantages. The use of mathematical programs or artificial models of resin material to simulate real conditions is not particularly ideal.

In order to have a more accurate model, the use of natural anatomic specimens is recommended. Dry skulls are thus used as experimental models because, although they do not present cartilage and fibrous tissues, at least the trabeculae and other anatomic features are the same as those found in vivo.

One method enabling direct use of the object being studied, and which has been used in several fields of dentistry, is holographic interferometry. This method allows the detection of minute movements of the order of nanometers, as well as overall qualitative and quantitative visualization of the trajectory of the tensions generated upon load application. Holographic interferometry has been used to evaluate stress in extracted teeth (4), metallic and ceramic crowns $(5,6)$, dental implants (7), removable dentures (8) and craniofacial displacements caused by external force in orthodontic application (9-12).

Holography follows a different principle from conventional photography. A laser is needed to produce a coherent, monochromatic light beam. The difference

Correspondence: Profa. Dra. Tomie Nakakuki de Campos, Faculdade de Odontologia, USP, Departamento de Prótese Dentária, Avenida Professor Lineu Prestes, 2227, Cidade Universitária 05508-900 São Paulo, SP, Brasil. Tel: +55-11-3091-7888. Fax: +55-11-3091-7640. e-mail: tncampos@usp.br 
in phase between a reference ray and the object ray (to be analyzed) produces an interference pattern that is recorded on a high-resolution photographic plate (hologram). When developed and suitably exposed to laser light, this hologram reconstructs a three-dimensional image of the object. Resolution is that of the order of the laser wavelength or that of a photographic film (13).

The reconstructed image of the hologram contains most of the information of the object. Additionally, there is total 1:1 correspondence between image and object, and there is parallax essentially in all directions, unlike three-dimensional photography, which does not have parallax (13).

The use of macerated skull as an experimental model in holography has, however, been questioned recently. Given that the process of maceration leads to bone drying and loss of fibrous connective tissue, a question remains as to whether the results obtained with macerated skulls could be transferred to the in vivo situation.

Because the holographic method is highly sensitive to small bone displacements and deformations, and given the controversy among researchers as to the use of macerated skulls, and the difficulty of obtaining fresh (post-mortem) human skulls, the purpose of this study was to compare the distribution of tensions produced under static load in fresh (control), macerated and fixed dog mandibles. The hypothesis was that the use of macerated bone like a model to study the stress distribution by means of holographic method could produce different results in comparison to fresh bone specimens.

\section{MATERIAL AND METHODS}

The study design was approved by the local Ethics in Research Committee (Process N.122/2000). The mandibles of 6 dogs (Canis familiars) aged approximately 4 years and weighing $12 \mathrm{~kg}$ were used. After sedation and euthanasia of the animals, the mandibles were surgically removed and all the surrounding soft tissues (skin, mucosa, ligaments, muscles and gingival tissue) were removed. Mandibles were then cut through the mental region using a scalpel blade.

A special device for fastening the hemi-mandibles was designed and assembled to standardize the characteristics of load application during the experiment in relation to intensity, point of application, direction, as well as to enable the return of the hemi-mandibles to the initial position after the maceration and formalin-fixing procedures. The hemi-mandibles were placed in such a way that load incidence would be at the incisal edge of the canine, simulating occlusion with the opposing tooth. The mandibular ramus was fixed in a metal box by screws and self-polymerizing acrylic resin was poured into the box. This set was fastened to the device by means of a clip-together system enabling the correct repositioning during the experiment (Fig. 1).

After initial holograms were taken, 12 fresh hemi-mandibles were assigned to 2 groups: 6 hemimandibles were fixed in $10 \%$ formalin for 2 weeks and 6 were macerated and dried using African beetles (Dermestes sp).

A He-Ne laser (Model 845; Newport Research, Irvine, CA, USA), a shutter controller and a $0.8 \mathrm{KVA}$ voltage stabilizing unit (MK 7000 GR; Savage, Irvine, CA, USA) were used to take the holograms. The laser was emitted continually by a direct current power supply. The laser beam had an output power of $30 \mathrm{~mW}$ and $633 \mathrm{~nm}$ wavelength. The following devices were set upon the holographic table: a spatial filter (Newport), a mirror, magnetic supports (Newport), highresolution film (AGFA - Holotest 8E75 - 5000 lines/ mm; AGFA Corporation, Ridgefield Park, NJ, USA) and the hemi-mandible holding device. All components were secured on an optical table buffered by compressed air (Newport) in order to avoid vibrations. A shutter with electronic exposure control was used to control exposure time for the holographic plate. The experiment was carried out in a totally dark, draft-free environment.

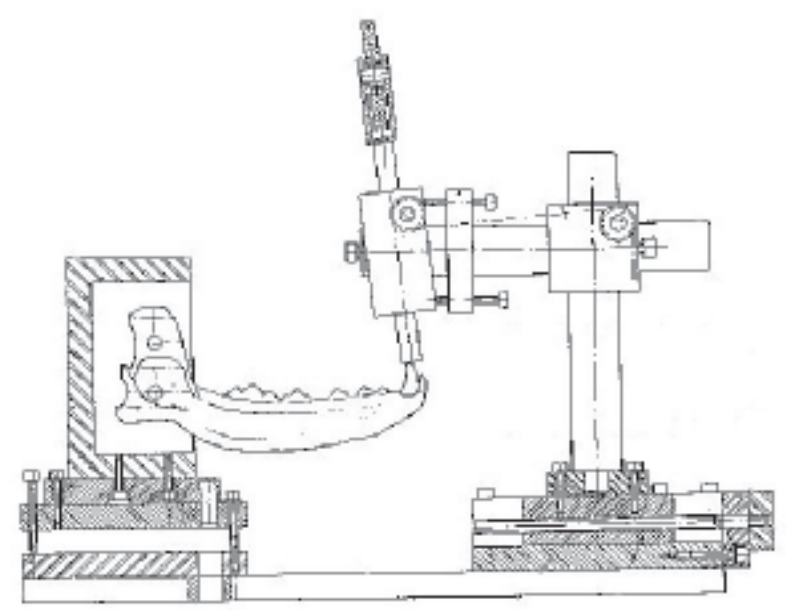

Figure 1. Device used to hold and position the hemi-mandibles. 
When activated, the laser illuminated the surface of the tension-free hemi-mandible and was reflected (object beam), reaching the holographic film. At the same time, beams from the same laser source hit the mirror. The reflected beam (reference beam) interacted with the object beam to produce a hologram on the film.

The hemi-mandible was subjected to a $100 \mathrm{~g}$ static load. The laser was projected onto the hemimandible and produced a second hologram on the same film by the same process. The film was developed and fixed. The incidence of laser light upon the developed film showed the image of the mandible with a pattern of fringes, caused by the interference produced by superimposing the two holograms. The image was captured by a CCD camera (Model KP-M1; Hitachi Denshi Ltd, Woodburg, NY, USA) and digitally recorded (Fig. 2).

Because tension moves perpendicularly to the fringes, it is possible to evaluate tension distribution within the body of the mandible quantitatively since the higher the number of fringes, the greater the tension transmitted and the greater the displacement produced between the original surface and the surface that is subjected to load. Qualitative evaluation is achieved by observing the aspect and direction of the fringes (8).

The theory of fringe formation in holographic interferometryhas been shown in other studies $(14,15)$. The following equations (16), using data of Figure 3, were used for quantitative measurement of displacement. For light fringes: $\mathrm{d}=\mathrm{n} . \mathrm{l} / \mathrm{2}$. $\cos \mathrm{g} \cdot \cos \mathrm{q}$, where: $\mathrm{d}=$ displacement; $\mathrm{l}=$ =wavelength; $\mathrm{n}=$ light fringe number; $\mathrm{q}=$ bisector angle between the direction of illumination and direction of observation; $\mathrm{g}=$ angle between

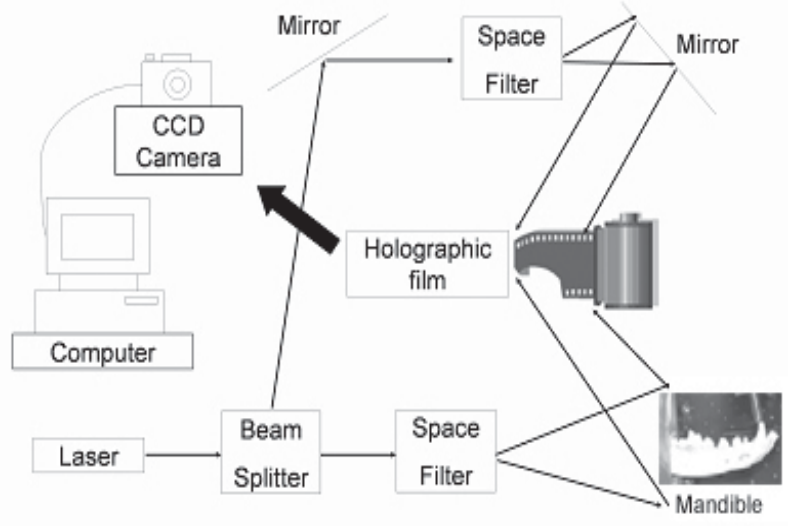

Figure 2. Schematic presentation of the holographic set up. sensitivity vector and displacement vector. For dark fringes: $d=(2 n+1) . l / 4$. $\cos g$. $\cos q$, where: $n=$ dark fringe number.

\section{RESULTS}

\section{Qualitative Analysis}

The holographic images showed that: 1) The fringes were more widely spaced in fresh hemimandibles and their number was smaller when compared to those of the fixed and macerated specimens. The macerated hemi-mandibles presented more fringes, with smaller spaces between them; 2) A change in the direction of fringes in the tooth and bone was recorded in the fresh hemi-mandibles. In the fixed and macerated specimens, the direction of fringes remained unchanged; 3) Spacing between the fringes was smaller near the point of load application and increased progressively along the mandible towards the fixed extremity; 4) The pattern of fringes was also different in direction; in fixed and macerated specimens the fringes showed greater inclination than in fresh hemi-mandibles, meaning that they underwent torsion.

Figures 4, 5 and 6 show images of specimens of fixed right hemi-mandible, fresh left hemi-mandible and macerated left hemi-mandible, respectively.

\section{Quantitative Analysis}

Data relative to the comparison between fresh and fixed specimens as well to the comparison between

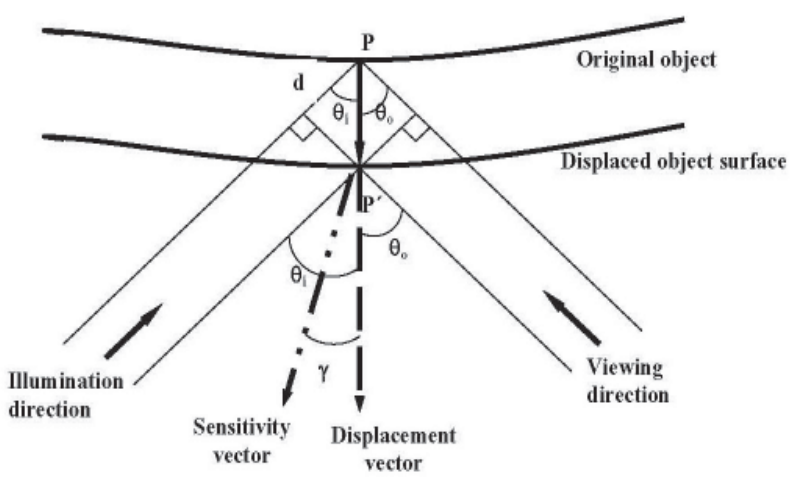

Figure 3. Diagram of displacement (d), angles $\left(\theta_{\mathrm{i}}, \theta_{0}\right.$ and $\left.\gamma\right)$, displacement vector and sensitivity vector. 
fresh and macerated specimens are presented on Tables 1 and 2, respectively.

The paired t-test and Wilcoxon non-parametric test were applied to the data. There was a statically significant difference $(\mathrm{p}<0.05)$ between the means obtained for the fresh hemi-mandibles and those obtained for the fixed and macerated hemi-mandibles. In addition, there was an approximate two-fold difference between the fresh-fixed and fresh-macerated states.

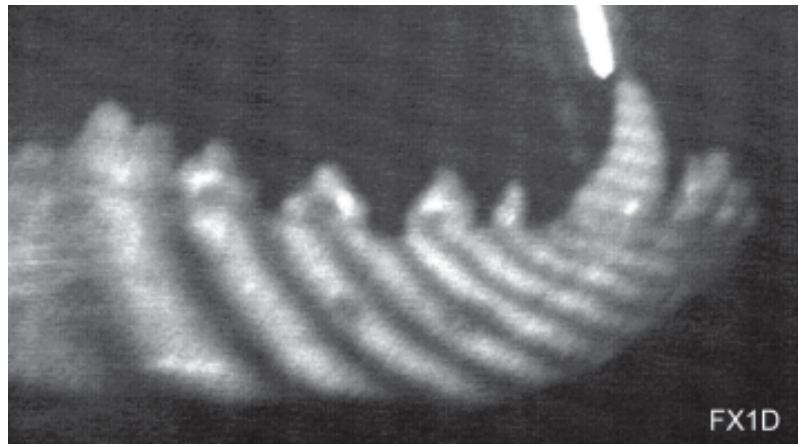

Figure 4. Holographic image of a fixed right dog hemi-mandible.

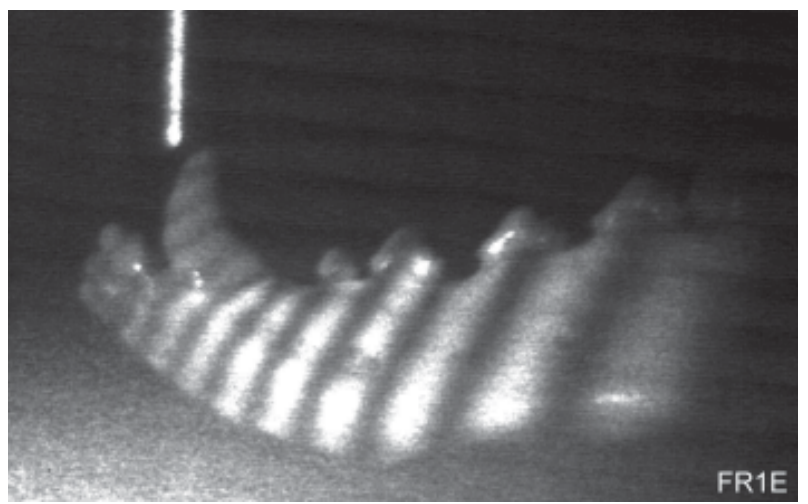

Figure 5. Holographic image of a fresh left dog hemi-mandible.

Table 1. Displacement values (in $\mathrm{nm}$ ) for fresh and formalinfixed specimens.

\begin{tabular}{lll}
\hline & Means $( \pm$ SD) & Median \\
\hline Fresh & $1,765 \pm 1,049$ & 1,262 \\
Formalin-fixed & $2,961 \pm 600$ & 3,099 \\
\hline
\end{tabular}

\section{DISCUSSION}

The principle of holographic interferometry states that the displacement caused by the action of a force on a body is directly proportional to the number of fringes, and its direction is perpendicular to that of the fringes. It is also known that the force is directly proportional to the displacement (Hooke's law), i.e., force and displacement travel in the same direction. Thus, by analyzing the number of fringes and the displacement produced, one can refer to the direction of the tensions.

Fresh hemi-mandibles were thus seen to transmit less tension than the corresponding fixed and macerated samples. The experiment began immediately after euthanasia of the animals, and the presence of fresh fibrous connective tissue may have dampened the action of the applied force.

Additionally, another factor that may have aided tension dissipation is the hardness of the bone. Yamada (17) stated that the hardness of dry compact bone is 1.4 times greater than that of fresh bone, and that formalinfixed bone is 1.1 times harder than fresh bone. By analogy, if a rigid bar is used to make a lever, a given

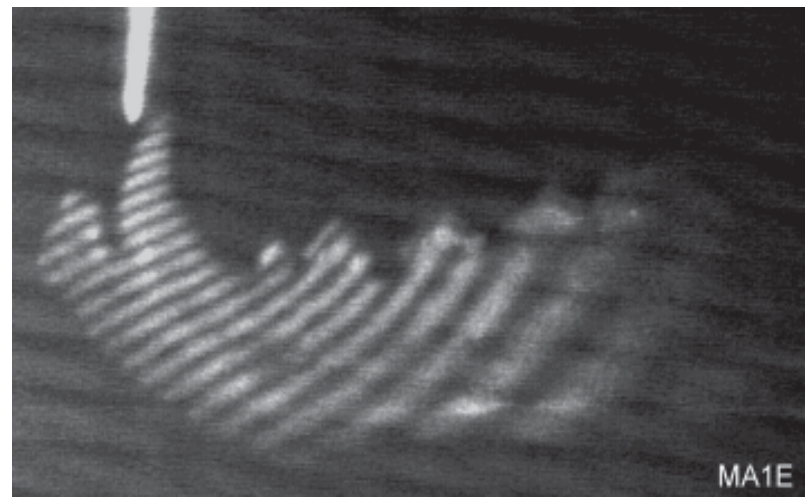

Figure 6. Holographic image of a macerated left dog hemi-mandible.

Table 2. Displacement values (in $\mathrm{nm}$ ) for the fresh and macerated specimens.

\begin{tabular}{lll}
\hline & Means $( \pm$ SD) & Median \\
\hline Fresh & $2,181 \pm 941$ & 2,328 \\
Macerated & $4,231 \pm 1,183$ & 3,859 \\
\hline
\end{tabular}


result will be obtained at the opposite end; if the same load is applied to a less rigid bar with the same dimensions, there will be a lower-intensity result at the opposite end.

In a previous study (10), moisture in fresh dog skulls may have influenced their results in comparison to macerated skulls, by making them less rigid and leading to a less pronounced displacement of bone. However, Govaert and Dermaut (11), while attempting to improve the condition of dry skull as an experimental model for orthopedic studies, kept macerated dog skulls in relative humidity ranging from 40 to $100 \%$. They found that the displacements of maxillas did not coincide with in vivo measurements.

In spite of these findings, macerated skulls are still used as study models (12). Therefore, it is important to emphasize that macerated bone specimens have a different behavior when compared to that of fresh bones.

The time elapsed post-mortem and the fixation in $10 \%$ formalin probably caused some level of rigidity in the periodontal ligament, in such a way that transmission of tensions occurred, qualitatively speaking, in the same way as with macerated samples. Because of the short time of formalin fixing, significant changes in the biochemical composition of the bone tissue may not have occurred. Boskey et al. (18) compared samples of bone tissue fixed in formalin (for 11 days) and fresh frozen samples, and found that mineral and lipidic parameters were not affected. They stated that formalin fixing causes agglutination of collagenous fibers.

In the present study, the macerated specimens presented a larger number of fringes, with smaller spacing between them. Therefore, tensions transmitted were more intense than in fresh samples, corroborating the results of Clerk et al. (10), who used speckle interferometry. This method, however, is not as accurate as holographic interferometry because it uses only the object beam to form the image.

The results of this investigation did not converge with the findings of Kannan (19), who found little difference in magnitude in the tensions developed in vivo and in dry monkey skulls, measured by means of load cells. One drawback in the use of load cells is that they are activated according to deformation in the surface which they are attached to. Thus, the load cell measures local deformation, and it is known that the elasticity module of the bone depends also on its location. Several load cells would be necessary to produce an overall mapping of the distribution of tensions. Furthermore, the method of attachment of this device to the surface of the object under study may also influence its performance.

Billiet et al. (20), who were concerned with the action of the periodontal ligament, simulated its presence by putting Araldit 208 into the sockets of a dry skull. The influence of the periodontal ligament was clear in the present study, as it was observed a marked alteration in the direction of fringes located in the tooth and in the bone of the fresh hemi-mandibles. However, in the fixed and macerated specimens, the direction of the fringes underwent no marked change, but rather remained constant, with tooth and bone behaving as a single body. In all hemi-mandibles, the fringes were more compact in the region closest to the point of force application and spacing between fringes increased steadily along the length of the mandible, towards the fixed extremity. These images show that the tensions created in the area of application of force are more intense and that these tensions are dissipated and absorbed as they are transmitted along the mandibular bone.

Despite some limitations of the use of macerated anatomical specimens as an experimental model for certain studies, holographic interferometry is an efficient method for measuring minute displacements and for analyzing tension distribution. Because it is a nondestructive method, whose results can be obtained from the very object under study, it enables repeatability of the experiment. It does not require mathematical, virtual or artificial simulation of the evaluated object, as in the finite element or photoelasticity methods. Holography also allows tension distribution analysis along all the sample extension. For example, to study occlusal force dissipation, it is possible to verify the course of the force lines in the entire craniofacial complex, in addition to the underlying bone.

The holograms obtained in the present study revealed that there was a difference in the stress transmission among fresh, fixed and macerated mandibles. The fresh mandibles transmitted less tension that the fixed and macerated ones $(\mathrm{p}<0.05)$. In fact, stress transmission in the experimental conditions was twice as large as in the control group. A difference in the direction of stress transmission was also observed. The findings of this investigation suggest that the use of dry specimens in research and the inference of their results for an in vivo situation must be conservative. 


\section{RESUMO}

Frente à diversidade de comportamento do tecido ósseo, nas condições seca e úmida, este trabalho comparou a transmissão de tensões em mandíbulas de cães nas seguintes condições: frescas, fixadas e maceradas. Aplicou-se a interferometria holográfica de dupla exposição e os hologramas foram obtidos de 12 hemimandíbulas, sob carregamento estático (grupo controle). Em seguida, foram randomizadas em 2 grupos: 6 hemi-mandíbulas foram fixadas em solução de formol a 10\% e 6 foram maceradas. As amostras foram submetidas à mesma carga inicial e os respectivos hologramas foram obtidos. A análise dos hologramas mostrou que as amostras frescas transmitiram menos tensão que as amostras fixadas e as maceradas $(\mathrm{p}<0,05)$, e também houve diferença na direção percorrida pelas tensões. Em média, os grupos experimentais apresentaram o dobro de tensões em relação ao grupo controle. O método da interferometria holográfica mostrou-se eficiente para avaliar quantitativa e qualitativamente a transmissão das tensões geradas. Entretanto, dependendo do tipo de análise, a peça anatômica deve ser fresca, uma vez que os resultados podem diferir das amostras secas.

\section{REFERENCES}

1. Topbasi B, Gunday M, Bas M, Turkmen C. Two-dimensional photoelastic stress analysis of traumatized incisor. Braz Dent J 2001;12:81-84.

2. Lewgoy HR, Youssef MN, Matson MR, Bocangel JA, Netto CA, Amore R. Finite elements study of the FlexiPost and FlexiFlange post system in a maxillary central incisor. Braz Oral Res 2003;17:132-136.

3. Ueda C, Markarian RA, Sendyk CL, Lagana DC. Photoelastic analysis of stress distribution on parallel and angled implants after installation of fixed prostheses. Braz Oral Res 2004;18:45-52.

4. Batista LR, Muramatsu M, Mori M, Campos TN, Nakao E, Secco A. Study of stress distribution in loaded tooth using holographic interferometry method. In: Annals of the 16th Annual Meeting of the Brazilian Society for Dental Research; Águas de São Pedro. São Paulo: Brazilian Society for Dental Research; 1999. p. 155.

5. Chen TY, Chang GL, Wu SH. Holographic evaluation of the marginal fits of complete crowns loaded at the central fossa. Opt Eng 1995;34:1364-1368.

6. Uono CRH, Chorres JER, Batista LR, Gioso MA, Muramatsu M, Campos TN. Effect of different prosthetic restorative materials on occlusal load distribution. Holographic interferometry method. Rev Pós Grad Fac Odontol USP. 2007. In press.

7. Chorres JER, Campos TN, Uono CRH, Gioso MA, Muramatsu M. Qualitative analysis of stress distribution in tooth-implant and implant-supported prosthesis by means of holographic interferometry method. RPG Rev Pós Grad 2005;12:412-416

8. Pezzoli M, Appendino P, Calcagno L, Celasco M, Modica R. Load transmission evaluation by removable distal-extension partial dentures using holographic interferometry. J Dent 1993;21:312-316.

9. Dermault LR, Beerden L. The effects of class II elastic force on a dry skull measured by holographic interferometry. Am J Orthod 1981;79:296-304.

10. Clerk H, Dermaut L, Timmerman $H$. The value of the macerated skull as a model used in orthopaedic research. Eur J Orthod 1990,12:263-271.

11. Govaert L, Dermaut L. The importance of humidity in the in vitro study of the cranium with regard to initial bone displacement after force application. Eur J Orthod 1997,19:423-430.

12. Dermaut LR. The dry skull model in orthodontics. Verh K Acad Geneeskd Belg 2002;64:19-54.

13. Schwaninger B, Schmidt R L, Hurst RVV. Holography in dentistry. J Am Dent Assoc 1977;95:814-817.

14. Shchepinov V, Pisarev VS. Strain and stress analysis by holography and speckle interferometry. New York: John Wiley \& Son; 1996.

15. Katz DM, Blatcher S, Shelton JC. Quantification of holographic fringe data: comparison of intact and implanted femurs. Med Eng Phys 1998;20:114-123.

16. Batista LR, Muramatsu M, Campos TN. Stress analysis of fresh and macerated dog mandibles. Holographic interferometric double exposition method. Proc SPI 2003;4829:10121013.

17. Yamada H, Evans FG. Strength of biological materials. Baltimore: Williams \& Wilkins; 1970.

18. Boskey AL, Cohen ML, Bullough PG. Hard tissue biochemistry: a comparison of fresh-frozen and formalin-fixed tissue samples. Calcif Tissue Int 1982;34:328-331.

19. Kannan K. Effects of headgear traction on the facial skeleton of the monkey: a study with strain gauges. J Osaka Dent Univ 1982;16:112-136.

20. Billiet T, de Pauw G, Dermaut L. Location of the centre of resistance of the upper dentition and the nasomaxillary complex. An experimental study. Eur J Orthod 2001;23:263-273.

Accepted 23 August, 2006 